\title{
Impact of climate trends on tick-borne pathogen transmission
}

\author{
Agustín Estrada-Peña ${ }^{1}$, Nieves Ayllón ${ }^{2}$ and José de la Fuente ${ }^{2,3} *$ \\ 1 Department of Parasitology, Veterinary Faculty, University of Zaragoza, Zaragoza, Spain \\ 2 Instituto de Investigación en Recursos Cinegéticos, CSIC-UCLM-JCCM, Ciudad Real, Spain \\ ${ }^{3}$ Department of Veterinary Pathobiology, Center for Veterinary Health Sciences, Oklahoma State University, Stillwater, OK, USA
}

\section{Edited by:}

Rubén Bueno-Marí, University of

Valencia, Spain

Reviewed by:

José Antonio Oteo, Centro de

Investigación Biomédica de La Rioja,

Spain

Joseph Piesman, Center for Disease

Control and Prevention, USA

\section{${ }^{*}$ Correspondence}

José de la Fuente, Instituto de

Investigación en Recursos

Cinegéticos, Ronda de Toledo s/n,

13005 Ciudad Real, Spain.

e-mail: jose_delafuente@yahoo.com
Recent advances in climate research together with a better understanding of tick-pathogen interactions, the distribution of ticks and the diagnosis of tick-borne pathogens raise questions about the impact of environmental factors on tick abundance and spread and the prevalence and transmission of tick-borne pathogens. While undoubtedly climate plays a role in the changes in distribution and seasonal abundance of ticks, it is always difficult to disentangle factors impacting on the abundance of tick hosts from those exerted by human habits. All together, climate, host abundance, and social factors may explain the upsurge of epidemics transmitted by ticks to humans. Herein we focused on tickborne pathogens that affect humans with epidemic potential. Borrelia burgdorferi s.l. (Lyme disease), Anaplasma phagocytophilum (human granulocytic anaplasmosis), and tick-borne encephalitis virus (tick-borne encephalitis) are transmitted by Ixodes spp. Crimean-Congo hemorrhagic fever virus (Crimean-Congo hemorrhagic fever) is transmitted by Hyalomma spp. In this review, we discussed how vector tick species occupy the habitat as a function of different climatic factors, and how these factors impact on tick survival and seasonality. How molecular events at the tick-pathogen interface impact on pathogen transmission is also discussed. Results from statistically and biologically derived models are compared to show that while statistical models are able to outline basic information about tick distributions, biologically derived models are necessary to evaluate pathogen transmission rates and understand the effect of climatic variables and host abundance patterns on pathogen transmission. The results of these studies could be used to build early alert systems able to identify the main factors driving the subtle changes in tick distribution and seasonality and the prevalence of tick-borne pathogens.

Keywords: tick, model, genetics, climate, Borrelia, Anaplasma, virus

\section{INTRODUCTION}

Ticks are obligate hematophagous ectoparasites of wild and domestic animals and humans that are classified in the subclass Acari, order Parasitiformes, suborder Ixodida, and distributed from Arctic to tropical regions of the world. Despite efforts to control tick infestations, ticks and the pathogens they transmit continue to be a serious constraint to human and animal health worldwide (de la Fuente and Kocan, 2006).

Several events that occurred during the final decades of the twentieth century and the beginning of the twenty-first century suggest a rise of tick-borne infections worldwide. These events include recent national and regional epidemics of known diseases such as tick-borne encephalitis (TBE) in Central and Eastern Europe, Kyasanur forest disease (KFD) in Karnataka state in India, Crimean-Congo hemorrhagic fever (CCHF) in northern Turkey and the southwestern regions of the Russian Federation, and Rocky Mountain spotted fever (RMSF) in Arizona, United States, and Baja California, Mexico (Pattnaik, 2006; Randolph, 2008; Maltezou et al., 2010; McQuiston et al., 2010). Globally, the recognized number of distinct and epidemiologically important diseases transmitted by ticks has increased considerably during the last 30 years. For example, more than 10 newly recognized spotted fever rickettsioses have been identified since 1984 (Parola et al., 2005; Paddock et al., 2008). In the United States, the list of national notifiable diseases include four tick-borne diseases, Lyme disease (Borrelia burgdorferi s.l.), human granulocytic anaplasmosis (HGA; Anaplasma phagocytophilum), human babesiosis (Babesia spp.), and human monocytic ehrlichiosis (Ehrlichia chaffeensis), each of which has increased steadily in average annual incidence. From 2000 to 2007, the incidence of infections caused by B. burgdorferi, A. phagocytophilum, and E. chaffeensis increased linearly (Bacon et al., 2008). Although advances in molecular technology have contributed to the identification of these pathogens, rapidly expanding pathogen diagnosis and increasing incidence have raised concerns about the accuracy of case counts and epidemiology reports (Mantke et al., 2008). The problem of analyzing the incidence of tick-borne pathogens in humans is the concurrency of factors affecting the whole system such as climate, driving the life cycle of the ticks, the availability, occurrence and seasonal patterns of competent reservoirs, and social habits, leading the 
contact with tick-infested areas need to be considered. All these factors should be analyzed with increasing levels of complexity that obscure the relationships between climate and the final impact of tick-borne pathogens.

Ticks and tick-borne pathogens have co-evolved molecular interactions involving genetic traits of both the tick and the pathogen that mediate their development and survival (Narasimhan et al., 2002, 2007; Kocan et al., 2004; de la Fuente et al., 2007a; Zivkovic et al., 2009; Rikihisa, 2010). These mechanisms are not well defined and the impact of environmental factors such as climate adds additional complexity to their study. However, the complexity of tick-pathogen relationships are emerging to show that it is difficult to describe a simple effect on the cascade of social and biological events affecting the transmission of tick-borne pathogens.

In these review, we evaluated pathogens that infect humans with epidemic potential such as B. burgdorferi s.l. (Lyme disease), $A$. phagocytophilum (human granulocytic anaplasmosis; HGA), and tick-borne encephalitis virus (TBEV; TBE) and Crimean-Congo hemorrhagic fever virus (CCHFV; CCHF). These pathogens are transmitted by Ixodes spp. and Hyalomma spp. ticks (de la Fuente et al., 2008) and were used to discuss how these tick species occupy the habitat as a function of different environmental factors, and how these factors together with molecular events at the tickpathogen interface impact on tick survival and seasonality and pathogen transmission. The results of existing models could be used to build early alert systems able to identify the main factors driving changes in tick distribution and seasonality and the prevalence of tick-borne pathogens.

\section{EFFECT OF CLIMATE AND OTHER ABIOTIC AND BIOTIC FACTORS ON TICK DEVELOPMENT, SURVIVAL, AND QUESTING}

As many other arthropods, ticks are very sensitive to climate. Ticks spend most of their life cycle in the environment, and all tick life cycle stages are dependent on a complex combination of climate variables for development and survival. Host availability and vegetation significantly modulate the dynamics of tick populations. They probably have smaller contributions than climate in delimiting tick distribution as climate is probably the major driver to the presence or absence of a tick species in a given territory (Cumming, 2002). However, vegetation is a great modifier of the local weather or the so-called microclimatic conditions, the one that the ticks must adapt to for development and survival. Though many animal species can serve as tick hosts, there are several determinants of host suitability and the specificity of tick-reservoir host-pathogen relationships is key to our understanding of the complex processes conditioning the transmission of pathogens by ticks (Randolph, 2009). For example, host availability in time and space is an important determinant of tick bionomics. Shelter and protection from environmental extreme conditions are critical to tick survival, because questing and diapausing ticks are vulnerable to extremes temperatures and humidity.

Concerns exist about how predicted climate changes may alter tick-host-pathogen relationships and particularly tick potential for invasion of new areas and pathogen transmission. Although surveillance and reporting of changes in the distribution of tick populations is generally inadequate, some well-documented reports support the slow but apparently continuous expansion of the historical frontiers of some tick species into areas where they were previously absent (Gray et al., 2009). Warmer temperatures have been suggested as the main driver of some tick geographic range changes (Lindgren et al., 2000; Danielova et al., 2006). However, the potential influence of changing rainfall patterns has largely been ignored although this may have a greater effect than temperature on the ability of tick populations to establish in new areas. Invasive events (the transportation of an exotic tick species into an area far from its native range) are also well-documented and seem to be related to unrestricted domestic animal movements or over-abundance of certain wild hosts. Finally, there is little doubt that human-induced changes in abiotic (climate, land cover, habitat structure) and biotic (distribution and abundance of tick hosts) conditions have occurred over the past few decades, and there is equally indisputable evidence for the increase in recorded human cases of some tick-borne diseases (Randolph, 2009).

Many tick species are exophilous, meaning that they develop and quest in open habitats, not in the protected environment of a shelter as do the endophiluous ticks. The ticks have three developmental instars, larvae, nymphs, and adults that feed on one (one-host ticks) or multiple (two- and three-host ticks) animal hosts. Ticks take a continuous blood meal on the same host for 3-10 days, depending on the instar. When fully engorged, ticks fall off their host and undergo development to the next instar. The mortality observed during tick development is regulated by water losses, which in turn are greatly influenced by the temperature and the physical properties of the arthropods cuticle. Climate thus affects tick survival mostly during non-parasitic periods of their life cycle because ticks survival and host-seeking activity is inhibited outside certain ranges of temperature and rainfall (Randolph, 1997; Ogden et al., 2004). If developing and host-seeking ticks suffer mortality at an approximately constant rate in nature (Vail and Smith, 1998), then the lower the temperature, the longer is the developmental cycle and the higher is tick mortality. Therefore, warmer than current climate conditions would favor the presence of permanent populations of the tick species living across the northern temperate zone, where water stress is not an important factor. Therefore, climate may contribute to increased tick abundance (because faster development and lower mortality) and the probability to survive in a newly colonized territory (Ogden et al., 2004). However, this relationship is not lineal. It is important to stress that relative humidity is not an adequate concept to understand water stress in ticks. Low air water contents are responsible of water losses in ticks (like in any other arthropod). An increased in temperature contributes to desiccation by water losses (Perret et al., 2000, 2003). The temperature, together with the deficit in water content of the air are thus the drivers of tick desiccation.

Climate can affect not only tick development and mortality, but also their activity rates, a feature that deeply affects infestation risks for humans and the intensity of tick infestations in reservoir hosts. Questing is the mechanism by which ticks find a host, climb on it, and feed. Ticks quest at variable heights in the vegetation, driven by factors such as temperature and relative humidity (Vail and Smith, 2002; Busby et al., 2012). It is known that different tick species, and even different instars of the same species, may quest at 
different heights, therefore experiencing different mortality rates at various temperatures.

\section{IMPACT OF WEATHER-INDUCED TICK STRESS RESPONSE ON TICK SURVIVAL, QUESTING, AND PATHOGEN TRANSMISSION}

The heat shock and other stress responses are a conserved reaction of cells and organisms to elevated temperatures and other stress conditions such as toxicity and pathogen infection (Tutar and Tutar, 2010). Crucial to cell survival is the sensitivity of proteins and enzymes to heat inactivation and denaturation. Therefore, adaptive mechanisms exist that protect cells from the proteotoxic effects of heat stress. The heat shock proteins (HSPs) and other stress response proteins (SRPs) protect cells and organisms from damage, providing higher levels of tolerance to environmental stress.

Tick HSPs and other SRPs such as glutathione- $S$-transferase, selenoproteins, metallothioneins, and ferritin have been shown to be involved in the cellular response to different stress conditions such as heat shock, oxidative stress, tick attachment, blood feeding, and pathogen infection (Macaluso et al., 2003; Mulenga et al., 2003, 2007; Rudenko et al., 2005; Ribeiro et al., 2006; de la Fuente et al., 2007b; Rachinsky et al., 2007, 2008; Hajdusek et al., 2009; Zivkovic et al., 2009; Kongsuwan et al., 2010; Lew-Tabor et al., 2010; Villar et al., 2010; Busby et al., 2012). For example, recent studies demonstrated that the stress response is activated in ticks and cultured tick cells after Anaplasma spp. infection and heat shock (Villar et al., 2010; Busby et al., 2012). However, under natural vector-pathogen relationships such as those occurring in I. scapularis infected with A. phagocytophilum, HSPs, and other SRPs are not strongly activated, probably reflecting tick-pathogen co-evolution (Villar et al., 2010). Nevertheless, at least as shown by proteomics analysis of I. scapularis ISE6 tick cells in response to $A$. phagocytophilum infection, some HSPs such as the HSP70 family are over-expressed while other putative HSPs such as HSP20 are under-expressed in infected cells (Villar et al., 2010).

Tick questing behavior affects host-seeking activity and pathogen transmission through the interaction of several factors including tick stress response (Belozerov, 1982; Daniel and Dusbabek, 1994; Randolph, 2004). The effect of temperature and relative humidity on $I$. scapularis questing behavior and abundance has been demonstrated in field and laboratory studies (Schulze et al., 2001; Vail and Smith, 2002; Busby et al., 2012). Lefcort and Durden (1996) demonstrated the effect of pathogen infection on ticks questing behavior by showing that infection with $B$. burgdorferi negatively affects adult $I$. scapularis questing behavior. Although still controversial, Herrmann and Gern (2010) provided evidence that that infection with B. burgdorferi and $B$. afzelii confers survival advantages to $I$. ricinus under challenging thermohygrometric conditions.

Recent studies demonstrated that subolesin and HSPs are involved in the control of I. scapularis response to the stress produced by heat shock, blood feeding, and A. phagocytophilum infection (Busby et al., 2012). These results showed that at high temperatures and during blood feeding, when $h s p 20, h s p 70$, and subolesin are over-expressed, I. scapularis ticks are protected from stress and pathogen infection and have a higher questing speed.
These responses help I. scapularis to increase survival by inducing stress responses and preventing desiccation because higher water losses at high temperatures with higher questing speed to increase chances to attach to a host. Because pathogen infection occurs during blood feeding, ticks also have developed a protective response to limit pathogen infection levels, also contributing to their survival.

Taken together, these results suggest a connection between tick stress response, questing behavior, and pathogen transmission. Tick stress response is activated as a consequence of different stress conditions such as those caused by temperature changes, blood feeding, and pathogen infection. The stress response counteracts the negative effect of heat shock and pathogen infection on tick questing behavior and increase tick survival, those playing an important role in pathogen transmission and the adaptation of tick populations to challenging environmental conditions.

\section{IMPACT OF CLIMATE TRENDS ON TICK-PATHOGEN TRANSMISSION BORRELIA BURGDORFERI S.I., THE CAUSATIVE AGENT OF LYME DISEASE}

Lyme disease is caused by B. burgdorferi s.l. infection and is transmitted by Ixodes spp. ticks. Lyme disease is one of the most prevalent human arthropod-borne diseases in United States and Europe (Bacon et al., 2008; Gray et al., 2009). However, Lyme disease records in Europe are commonly produced by large administrative divisions, which are extremely heterogeneous in climate, abundance of reservoir hosts and landscape composition, all factors affecting pathogen prevalence in the tick vector (Estrada-Peña et al., 2011a). The association between B. burgdorferi and its vector is quite specific and only a small group of tick species within the genus Ixodes are known to be vector competent. These ticks have infections that spread from the gut to the salivary glands for transmission to susceptible hosts. Ixodes spp. ticks feed upon small to medium-sized reservoir hosts (usually mice, birds, and lizards) as immatures, and medium to large hosts (ungulates) as adults. Host range for all stages of Ixodes spp. is much broader than for most other ticks (Keirans et al., 1999). Microclimatic and biologic requirements for Ixodes ticks that transmit the spirochete are: (1) suitable host availability, (2) temperature fluctuations between -10 and $+35^{\circ} \mathrm{C}$, with tolerance to the extremes for only brief periods, and (3) a constant relative humidity not lower than $80 \%$ in the air and near saturation in the soil. Therefore, the ticks have well quantified requirements for its development and survival.

A recent study by Ogden et al. (2004) demonstrated that, under the conditions in the northern United States, local populations of I. scapularis are not affected by water stress, therefore temperature and photoperiod would be the only regulatory variables of tick activity and development. Ticks acquire B. burgdorferi infection while feeding on an infected competent reservoir host, a species capable of transmitting infection. After molting, ticks quest for another host among the herbage of the woodland floor, and infected ticks will transmit the pathogen and infect any susceptible host they feed on. Two factors have facilitated the spread of B. burgdorferi in northern United States. First, the increasing population size and geographical range of I. scapularis ticks, which is believed to be driven by restored woodlands and growing 
white-tailed deer populations, an important tick host (Kurtenbach et al., 2006). Second, the role of migratory birds in the spread of feeding I. scapularis nymphs when flying from their winter quarters to northern territories in Canada (Ogden et al., 2005a,b). Not only these migratory birds can introduce ticks into new territories, but also move further north established tick populations, likely because warmer weather periods in autumn and winter. These studies complemented previous reports (e.g., Estrada-Peña, 2002) derived from models about the increasing suitability of the weather in United States to support permanent I. scapularis populations. Each of these weather-derived factors affect tick survival rates, influencing the densities of endemic tick populations and the threshold number of immigrating ticks needed to establish a tick population in a new focus.

The situation in Western Palearctic is very different (Kurtenbach et al., 2006). The temporal pattern of the incidence of Lyme disease in Europe seems to be more stable than in the northeastern United States, although local temporal fluctuations in tick infection prevalence have been recorded (Kurtenbach et al., 2006). Unlike in the northeastern United States, in Europe, most species or even subtypes of $B$. burgdorferi s.l. are specialized to infect different groups of vertebrates. $I$. ricinus, the main tick vector of $B$. burgdorferi in Europe, needs areas with a good cover of vegetation and a mat of decaying vegetation with a relative humidity of at least $80 \%$ during the driest times of the year (Gray, 2008). When it is too dry or too cold, ticks will withdraw to the litter area to prevent desiccation and freezing (Gray, 2008). Geographical range of I. ricinus ticks is limited in its northern, or high-altitude, range by temperature (Lindgren et al., 2000; Jouda et al., 2004) and in its southern range by humidity (Estrada-Peña et al., 2004). The ecology of the tick and its habitat in northern Africa, where the pathogen also circulates in a dry, Mediterranean type environment, has not been characterized. Due to the effect of temperature and humidity on I. ricinus, its activity varies in different regions. In central Europe, occurrence of ticks shows two peaks for all developmental stages, with maximum in May-June and September-October (EstradaPeña et al., 2004). In Northern Europe, these two peaks converge into a single maximum in the summer, although this pattern is not constant in all regions (Lindgren et al., 2000). Jouda et al. (2004) demonstrated that tick seasonality changes with variations in altitude. However, these bimodal or unimodal activity patterns may change from year to year in the same area (Jouda et al., 2004). In the Mediterranean, an adult tick maximum occurs between November and January, but nymphs are active in spring (Dsouli et al., 2006).

The association between the prevalence of B. burgdorferi in nymphal $I$. ricinus ticks exists across a large geographical range in the western Palearctic and this association is partially correlated with some continuous traits of the regional weather (Estrada-Peña et al., 2011a). Some climate gradients and phenological features together with habitat fragmentation provide better conditions for $B$. burgdorferi infection of $I$. ricinus and for the maintenance of highly tick-infected foci (Estrada-Peña et al., 2011a). Some studies have indicated the influence of tick life cycle traits on the distribution of B. burgdorferi genotypes in the United States as a consequence of different climate patterns affecting tick phenology. Kurtenbach et al. (2006) predicted and it was later confirmed by empirical data (Gatewood et al., 2009) that the asynchrony of infected nymphs and uninfected larvae favors pathogen persistence strategies, whereas synchrony of these tick stages combined with a short annual period of activity should favor short-lived strategies and the capacity for co-feeding transmission. Because the climate modulates such a tick phenology in keeping both larval and nymphal stages feeding on host at the same time or at different moments of the year, climate can be considered responsible for the persistence of different strains of B. burgdorferi s.l. in the United States and Europe. The abundance of infected ticks is determined not only by climate trends but also by the extrinsic incubation period of spirochetes in ixodid ticks, which equals the duration of development from larvae to nymphs that is climate sensitive (Randolph and Rogers, 2000). Therefore, patterns of abundance and genotype distribution of the populations of $B$. burgdorferi are shaped substantially by the environmental cues that act on the tick populations, whereas additional layers of complexity are introduced into the system by host population dynamics and the host immune response to both bacteria and the ticks.

\section{ANAPLASMA PHAGOCYTOPHILUM, THE CAUSATIVE AGENT OF HUMAN GRANULOCYTIC ANAPLASMOSIS}

Similar processes to those described for B. burgdorferi could be considered for A. phagocytophilum (formerly E. phagocytophila, E. equi, and A. phagocytophila), the causative agent of HGA and also transmitted by ticks of the I. ricinus complex. A. phagocytophilum was first identified and described in humans in 1994 (Dumler et al., 2001). HGA is an emerging zoonotic disease in Asia and Europe (Parola and Raoult, 2001) and is reported in the United States at a rate of 4.2 cases per million persons in 2008 (http://www.cdc.gov/anaplasmosis/stats/). A. phagocytophilum is widespread in many species of wild and domestic animals, including rodents, carnivores, equids, ruminants, and birds (Sréter et al., 2004). Although, the same tick species involved in the transmission of B. burgdorferi are also involved in the transmission of A. phagocytophilum, the range of competent reservoir hosts and tick vectors is different and involves a larger number of species, thus affecting the epidemiology of the disease. A. phagocytophilum has been detected in animals and ticks throughout the United States and in nearly all European countries, but the strains or variants and the resulting diseases vary with the geographic location (de la Fuente et al., 2005; Massung et al., 2006; Stuen, 2007; Reichard et al., 2009; Woldehiwet, 2010; Gaowa et al., 2012; Jin et al., 2012). Additionally, recent evidence suggested that pathogen strains infecting humans differ genetically from ruminant straits and may be maintained in nature in different reservoir hosts (de la Fuente et al., 2005).

Transmission of A. phagocytophilum was shown to be transstadial, in which infection is acquired by the feeding of larvae or nymphs on infected hosts and transmission occurring by the next tick stage, nymphs or adults (Hodzic et al., 1998). However, the low abundance of $I$. ricinus in some areas in which A. phagocytophilum has been identified suggests that other tick species may be involved in pathogen transmission (MacLeod, 1932; Holden et al., 2003; de la Fuente et al., 2004; Alberti et al., 2005; Cao et al., 2006; Naranjo et al., 2006; Barandika et al., 2008). Tick transmission of A. phagocytophilum variants by these tick species may have different transmission patterns and target hosts which have not 
been reported so far. Notably, Baldridge et al. (2009) demonstrated transovarial transmission of $A$. phagocytophilum variants in $D$. albopictus, which is of interest because this mode of transmission is not considered to occur with other Anaplasma spp. Transovarial transmission of A. phagocytophilum variants in nature would reduce their dependence on mammalian reservoirs. However, further studies on A. phagocytophilum transmission by different tick species and pathogen strains and variants are needed to fully define the role of ticks in the transmission of this pathogen.

Anaplasma phagocytophilum host infection levels at the time of tick feeding influence tick infection rates. The infection of $A$. phagocytophilum in I. scapularis nymphs correlated with the bacteremia level in the mouse blood (Hodzic et al., 1998). However, once ticks become infected, even with a low number of bacteria, pathogen replication in ticks appears to compensate for the low infection rates and enhanced transmission (Hodzic et al., 1998). Transmission of A. phagocytophilum by ticks was shown to occur between 24 and $48 \mathrm{~h}$ after tick attachment (Sukumaran et al., 2006).

Despite these advances in the study of tick-host-pathogen interactions, available information is not enough to model infection risks associated with $A$. phagocytophilum distribution and the effect of abiotic factors on pathogen transmission.

\section{TICK-BORNE ENCEPHALITIS VIRUS, THE CAUSATIVE AGENT OF TBE}

Tick-borne encephalitis is caused by an important arbovirus of the genus Flavivirus. The disease is reported from many areas in central and northern Europe. The geographical range of TBE clinical cases do not overlap with the known distribution of the vector, $I$. ricinus, which is recognized as the only vector in Western Palearctic. Therefore, it is inferred that factors other than the simple presence of the vector, are driving the range of the virus.

Recent results show that tick saliva contains factors that modulate host inflammatory, coagulation and immune response to improve tick blood feeding and pathogen transmission (Jones et al., 1989; Alekseev et al., 1991; Labuda et al., 1993a; Randolph, 2009). This so-called "saliva-assisted transmission" (SAT) was reviewed by Nuttall and Labuda (2008). Inoculation of salivary glands extracts and TBEV into laboratory animal hosts resulted in enhanced transmission from hosts to nymphal ticks when compared with pathogen inoculation alone (Alekseev et al., 1991; Labuda et al., 1993b). SAT helped to explain the mechanism behind the equally novel observation of TBEV transmission between cofeeding ticks in the absence of a systemic infection (Labuda et al., 1993a,b; Randolph, 2009).

Co-feeding transmission imposes constraints because it requires co-feeding by at least two tick stages in synchrony in their seasonal activity (Randolph et al., 2000). The long and slow life cycle typical of temperate tick species, caused by low temperaturedependent developmental rates and overwinter diapause, slows the pace of pathogen transmission. As tick phenology is reset each year by winter conditions (Randolph et al., 2002), the critical stages (larvae and nymphs for TBEV) may emerge from diapause in more or less synchrony in the spring, depending on whether temperatures rise sufficiently rapidly to cross the threshold for larval activity (ca. $10^{\circ} \mathrm{C}$ mean daily maximum) soon after the threshold for nymphal activity (ca. $7^{\circ} \mathrm{C}$ mean daily maximum; Randolph and
Sumilo, 2007). The variability of thermal conditions associated with seasonal synchrony between tick stages has been identified as the key determinant of the focal distribution of TBEV across Europe (Randolph et al., 2000), allowing the predicted risk of TBE to be mapped using climatic surrogates sensed from space (Randolph et al., 2000).

Altogether, this information suggests that climate exerts an extreme control of the natural cycles of TBEV and delineates both their intensity (in terms of field tick prevalence rates) and their geographical distribution. According to the prevalent hypothesis outlined before, the climate at the beginning of the spring exerts a regulatory action on the synchrony of the active immature ticks, conditioning the necessary coexistence of nymphs and larvae on the same hosts. Because the short time of feeding for both larvae and nymphs, small changes in the temperature in that period may promote a lack of synchronicity of a few days, enough to prevent the "backward" transmission of the virus. These events have not yet been captured by a process-driven model, which could be a welcomed addition to our array of epidemiological tools, necessary to understand the TBEV epidemiology and design intervention for its prevention.

The situation is drastically different when series of human TBE cases are compared against a background of oscillating climatic conditions. It has been speculated that changes in climate, host abundance, social habitats, economic fluctuations, environmental changes, and to a lesser extent climate changes have increased the incidence of TBE (Lindgren and Gustafson, 2001; Zeman and Benes, 2004; Sumilo et al., 2006, 2007, 2008). However, it is very difficult to correlate series of human clinical cases against basic climatic features because climate has several collateral effects, not only affecting tick life cycle but also hosts and, most important, social habits. This has been demonstrated in a series of data for TBE cases in the countries of the Baltic Sea (Sumilo et al., 2007) and the Czech Republic (Zeman and Benes, 2004). It is thus hard to find a long, unbiased series of data on human TBE incidence, covering an adequate time, and then find simple correlations with raw climate features.

\section{CRIMEAN-CONGO HEMORRHAGIC FEVER VIRUS, THE CAUSATIVE AGENT OF CCHF}

A different situation exists regarding CCHFV, the causative agent of CCHF. One of Hoogstraal's conclusions in his review on the epidemiology of CCHF (Hoogstraal, 1979) stated that "Not a single substantial study has been made of interrelationships between the virus, [...] wild and domestic mammals, [...] and ticks during the 'silent' coursing of the virus in nature. It is disappointing to have to write [...] that there are still no detailed investigations on CCHF virus localization, multiplication, and dynamics in ticks." More than 30 years later it is disappointing to report that little has progressed in this area. The complex enzootic cycles of CCHFV are made up of a combination of interactions resulting in a seemingly focal geographic distribution range that does not appear to currently match that of competent vector species. These interactions include: (i) several tick species implicated as vectors, (ii) a wide array of (suspected) reservoir hosts for immature and adult stages of the ticks, (iii) trends in climate and (iv) social changes, and consequently thereafter ( $\mathrm{v}$ ) alterations in landscape and vegetation. A 
recent review (Estrada-Peña et al., 2012a) discussed the possibility of missing basic factors in our understanding of the epidemiology of CCHFV and some arguments that have been already rejected as drivers of virus reemergence. It is of interest to note that epidemics or active "silent" (inter-epidemics) CCHFV transmission occurs in areas where ticks of the genus Hyalomma are common. It has been proposed that other tick species are involved in the transmission of the virus. Some genera other than Hyalomma have been tested under strict laboratory conditions, demonstrating the presence of the virus in the tick after feeding on infected hosts (Swanepoel et al., 1983). The only constant feature of CCHFV foci is the presence, and in some cases increased abundance, of Hyalomma ticks. These results suggest that although other tick species may be competent vectors for the virus, Hyalomma ticks play the major role in virus transmission.

The tick genus Hyalomma is widespread in different ecological areas of the Palearctic and Afrotropical regions. Some species, like $H$. scupense (one- or two-host tick) and H. anatolicum (two- or three-host tick) prefer to feed on the same large ungulates (mostly cattle) during all developmental stages, and adopt a ridiculous life cycle. $H$. marginatum and $H$. rufipes are two-host ticks with immatures feeding on birds or small/medium-sized mammals and adults feeding on a larger wild and domestic ungulates (Apanaskevich, 2004). The principal species implicated in transmission of CCHFV in Eurasia are H. marginatum, $H$. turanicum, H. anatolicum, and $\mathrm{H}$. scupense (including the former $\mathrm{H}$. detritum, now considered a synonym of H. scupense; Guglielmone et al., 2010). The virus has been reported to survive throughout tick's life cycle and is transmitted transstadially and transovarially (Matser et al., 2009). The long survival of the virus in ticks is important CCHFV epidemiology, but there is still a dearth of knowledge regarding host exposure rates and host immune responses particularly in populations of short-lived birds, insectivores and lagomorphs.

Similar to other tick-borne diseases, climate trends have been commonly linked to outbreaks of CCHF clinical cases. However, social factors such as abandoned arable land (and therefore secondary vegetation growth) together with an increase in the abundance of wild animal hosts for ticks, may result in the amplification of tick populations (Vatansever, personal communication). Without a framework linking the response of the tick vector to subtle climate variations, it is only possible to speculate on the effect of climate on pathogen transmission. An assessment of the effects of climate on the presence of human CCHF clinical cases in Turkey included monthly values of several climate variables and concluded that climate was not different in sites with active foci of the disease as compared with sites where $H$. marginatum is common but human cases have not been reported (Estrada-Peña et al., 2011b). Studies in the focus of the disease in Turkey demonstrated that a high landscape fragmentation, compatible with conditions of high hosts and tick population movements and turnover, is a hallmark in areas with highest case incidence of CCHF in humans (Estrada-Peña et al., 2010). These reports concluded that it is not possible to predict, based solely on climate grounds, where new CCHF cases could appear in a reasonably near future. The recent finding of CCHFV in southern Europe (Estrada-Peña et al., 2012b) opened a yet speculative door about the potential real distribution of the virus in the Western Mediterranean. One of the most striking questions in the geographical distribution of CCHFV is the lack of clinical cases in western Mediterranean, west to the main distribution area of the pathogen, which ends at western Balkans. The analysis of the viral strain recorded in southwestern Europe suggested its close phylogenetic proximity with strains commonly reported from northern Africa and suggested that migratory birds might be behind such a particular spread of the pathogen.

Results suggest that the Hyalomma tick vector may spread into northern Europe as a consequence of warmer winters. Migratory birds have been repeatedly implicated in dispersing immature Hyalomma ticks. Each spring, many thousands of ticks are introduced in Europe by migratory birds from Africa (Hoogstraal et al., 1961, 1963). The level to which these birds may be exposed to African Hyalomma populations and subsequently import them into Europe depends upon the habitats they frequent, their ground feeding behavior and the timing of their departure. Owing to the earlier timing of bird arrivals in western Europe compared to the period for optimal nymphal molt in Africa, the likelihood of such importation is reduced (Knudsen et al., 2007). The northern limit of Hyalomma potential survival will depend upon how suitable the abiotic conditions are at the arrival site to facilitate molt of engorged immatures, as well as the availability of suitable hosts. Hasle et al. (2011) reported the presence of only seven immature $H$. rufipes on 713 migratory birds collected in the southern coasts of Norway. However, this result does not guarantee their survival under local climate conditions. Further investigation is required to determine whether or not such exotic tick species can survive and establish should they arrive to a suitable habitat and with available hosts. For example, $H$. rufipes from sub-Saharan Africa and the Nile River cannot survive in the environments of the Mediterranean basin or in the northern European latitudes. Studies demonstrated that the natural distribution of $H$. rufipes is sub-Saharan Africa and adjacent regions of Africa and Arabia along the Red Sea (Apanaskevich and Horak, 2008). The records of H. rufipes from Europe (Macedonia, Malta, and Turkey) and North Africa (except Egypt) are an apparent consequence of the dissemination of the immature stages by migratory birds from Africa, but do not represent permanent populations (Apanaskevich and Horak, 2008). However, studies have demonstrated that the northern distribution limit of H. marginatum, which is a Palearctic tick species, may be moving further north owing to the trend in the autumn and winter temperatures (Estrada-Peña and Venzal, 2007). The issue is thus the evaluation of the probabilities at which a bird with infected and feeding Hyalomma immatures may arrive to a given site in Europe, at the precise timing for optimal tick molt and survival.

Nothing is known about the molecular interactions at the tick-host-virus interface, probably because the high biosafety level required working with CCHFV. The characterization of the tick-host-virus interactions is essential to fully understand virus infection and transmission processes.

\section{MODELING RISKS FOR PATHOGEN TRANSMISSION AND EPIDEMIC POTENTIAL}

The most common strategy to estimate the potential geographic range of a species is to characterize the environmental conditions that are suitable for the species, and then identify where suitable 
environment is distributed in space. This is the fundamental strategy common to most distribution models. The environmental conditions that are suitable for a species may be characterized using either a statistical or a correlative approach. Statistical models aim to incorporate physiologically limiting mechanisms in a species tolerance to environmental conditions. The principal steps required to build and validate a correlative species distribution model are: (1) known species occurrence records and (2) a suite of environmental variables. Raw climate variables, such as daily precipitation records collected from weather stations are often processed to generate model inputs that are thought to have a direct physiological role in limiting the ability of the species to survive. The species occurrence records and environmental variables are entered into an algorithm that aims to identify environmental conditions that are associated with species occurrence. In practice, we usually seek algorithms that are able to integrate several environmental variables, since species are in reality likely to respond to multiple factors. Having run the modeling algorithm, a map can be drawn showing the predicted species distribution. The ability of the model to predict the known species distribution should be tested at this stage. A set of species occurrence records that have not previously been used in the modeling should be used as independent test data. The ability of the model to predict the independent data is assessed using a suitable statistic test. Once these steps have been completed, and if model validation is successful, the model can be used to predict species occurrence in areas where the distribution is unknown. Thus, a set of environmental variables for the area of interest is the input into the model and the suitability of conditions at a given locality is predicted. In many cases the model is used to "fill the gaps" around known occurrences.

A model to capture the range of suitable climate conditions for the tick I. ricinus based on occurrence records has been developed (Estrada-Peña, 1999, 2008). This model runs on a series of remotely sensed climate features, namely the average monthly temperature and the average normalized derived vegetation index (NDVI). NDVI is an indicator of plant photosynthetic activity and therefore used here as a surrogate for water stress as perceived by the tick. NDVI is the single variable that better explains the range of environmental suitability for $I$. ricinus (Estrada-Peña, 1999). Figure 1 shows the expected range for the I. ricinus colonization in a wide area of western Palearctic. After training the model, a relatively long series of data can be used as information for the modeling algorithm to predict the long-term changes of the index of habitat suitability for I. ricinus. Figure $\mathbf{1}$ also displays the trend in environmental (climate) suitability for the I. ricinus in the period 2000-2010. The model shows a clear increase in climate suitability and the possible expansion of tick populations into wide areas of southern Scandinavia, eastern Europe, and Baltic countries. These predictions agree with recent observations of increased abundance of the tick in these areas (Danielova et al., 2006; Jaenson et al., 2012). It is widely recognized that climate is not the only factor driving tick range expansion, because availability of key tick hosts may cause sharp changes in tick population abundance (Jore et al., 2011; Jaenson et al., 2012). Climate is just one of the factors involved, but the models trained only with climate as explanatory variables of tick occurrence produce a coherent result about the effects of climate on tick populations.

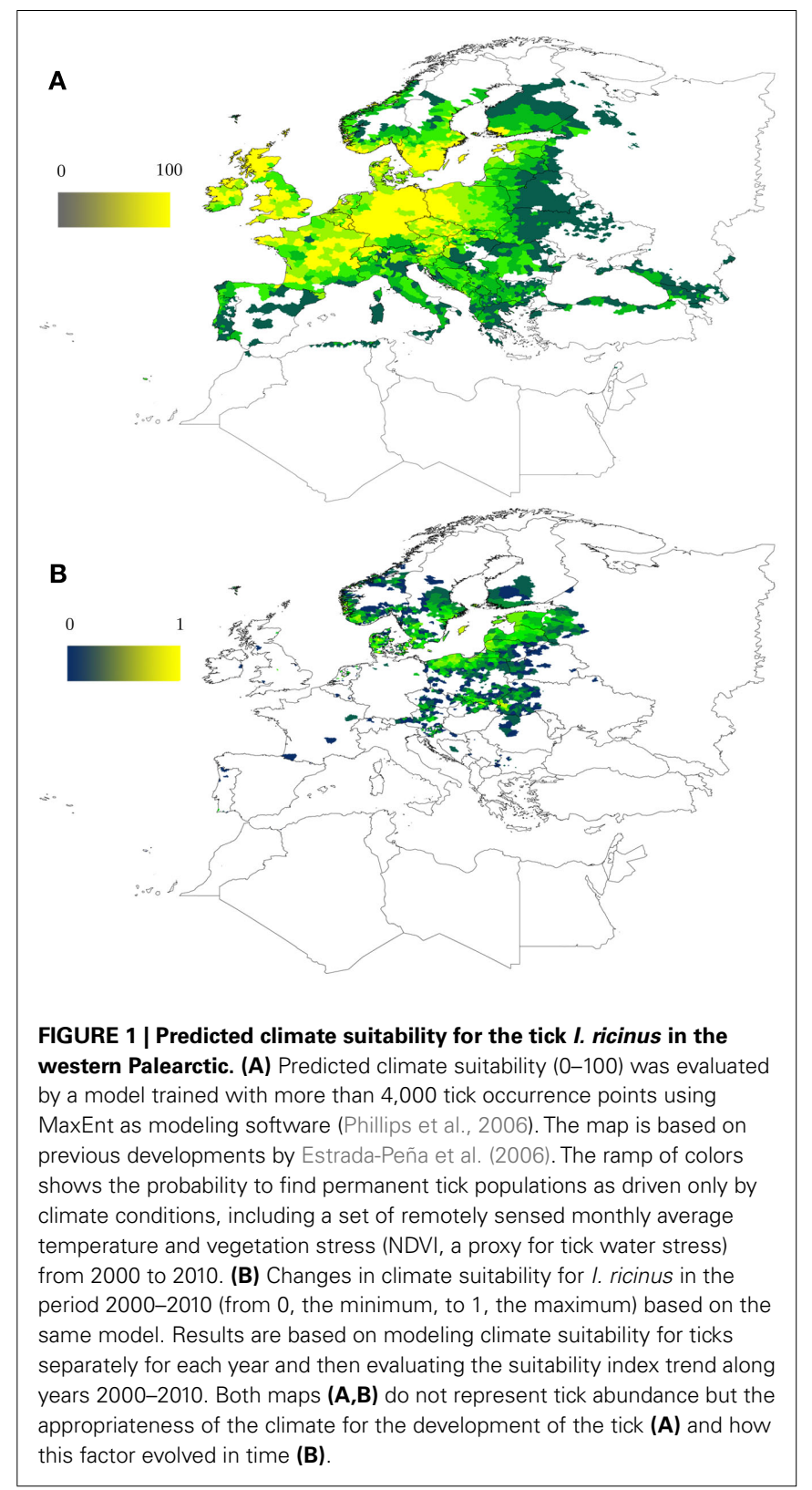

However, the many factors behind the complex tick-hostpathogen interface make this approach simplistic for the purpose of understanding pathogen transmission. If we aim to decipher how a pathogen can be sustained and spread, we need a processdriven model capturing the seasonal activity of the tick. A series of studies on the life cycle of I. scapularis and the transmission of $B$. burgdorferi were conducted by Ogden et al. (2005a,b). These models are built over the concept of the accumulated development, i.e., the different stages of the tick have a temperature over which the tick is activated and perform developmental processes. There is a species-specific threshold of temperature (e.g., a value of accumulated temperatures) over which tick development is completed. Therefore, the temperatures recorded at a given period indicate the fraction of tick development completed. The models by Ogden et al. (2005a,b) for the I. scapularis life cycle also incorporate 
adequate descriptions of tick questing periods and the infestation rates on hosts. These models were aimed to describe the spreading patterns of B. burgdorferi in southern Canada and northern United States, and to recognize the effect of key hosts in the prevalence rates by some pathogens in ticks.

While not explicitly aimed to address the concept, these deterministic models are focused on the understanding of the basic reproduction number, R0. The spread of pathogens is typically characterized by this index, which is defined as the expected number of secondary cases produced by a single primary case in a wholly susceptible population when there is a homogeneous and well-mixed population of hosts. In the case of the pathogens surviving in an Ixodes-reservoir rodent cycle, the duration of rodent infectivity for ticks must span any gap between the seasons of nymphal and larval activity (Randolph, 2001). The duration of infectivity is a crucial measure of fitness in different host species for vector-borne pathogens and particularly for B. burgdorferi in northeastern Unites States (Tsao et al., 2004). However, for $I$. scapularis-borne zoonoses investigated so far, recovery of rodents from acute, highly transmissible infections is not complete and the rodents remain persistently infective carriers that transmit infection to ticks with low efficiency (Derdáková et al., 2004; Ogden et al., 2005b). The potential capacity for B. burgdorferi or A. phagocytophilum to be transmitted between ticks co-feeding on the same host irrespective of systemic host infection adds further complexity to the transmission dynamics. Furthermore, relative rodent birth and death rates between nymphal and larval appearance each year very likely also affect pathogen transmission cycles (Schauber and Ostfeld, 2002).

These examples show that, for a complete understanding of the complex cycles among ticks, reservoir hosts, and pathogens, it is necessary to develop a system able to reliably predict, at least, the periods of activity of the tick vectors. It must also coherently compute the tick density-dependent mortality rates, which are a feature derived from the abundance of both ticks and hosts. A model displaying the seasonal patterns of the tick is thus necessary before R0 can be calculated for tick-transmitted pathogens. A statistical model derived from the relationship between the tick and the climate will probably provide a reliable picture of the geographical range of the tick, but not the environment necessary for the potential evaluation of $\mathrm{R} 0$.

A process-driven model for $H$. marginatum (Estrada-Peña et al., 2011b, 2012c) examined the potential effects of a changing environment on the colonization potential of the tick in areas outside its current range. This study specifically described areas where climatic features and a critical habitat configuration for host dispersal results in major changes in tick turnover. The study used a model based on host movement rules over the interface of the process-driven tick model, regulated by the daily climate obtained for a spatially interpolated $10 \mathrm{~min}$ grid over the target region. The results of this model, based on a dynamic evaluation of tick developmental and mortality rates, predicted different tick suitability areas when compared to a previously developed model based on tick occurrence patterns (Estrada-Peña and Venzal, 2007; Figure 2). Process-driven models tend to map a larger area of potential tick range, even if plotted at the same resolution of raw explanatory climate variables. This is probably because these

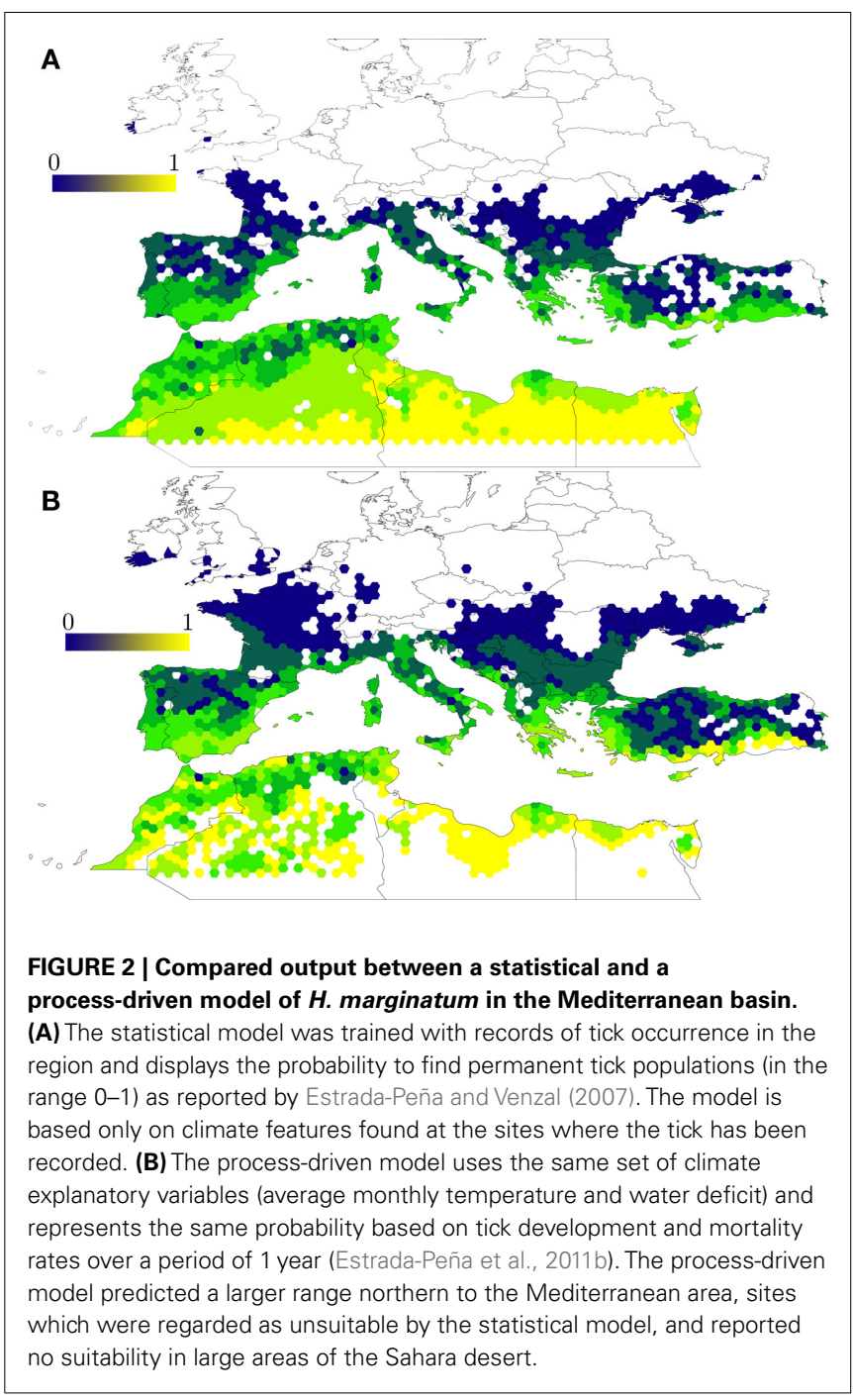

models use a higher number of features, therefore providing a better environment to develop a reliable background to evaluate $\mathrm{R} 0$ rates.

Climate scenarios for the years 2020, 2050, and 2080 on the life cycle of $H$. marginatum ticks in the western Palearctic showed that the net growth rate of tick populations increase in every scenario tested compared to current climate baseline. These results support the expectations of increased tick survival and increased population turnover in future climate scenarios. Such a model of host dispersal linked to the process-driven life cycle model demonstrated that current eastern (Turkey, Russia, Balkans) populations of $H$. marginatum are well separated and have little mixing with western (Italy, Spain, northern Africa) populations. The cold areas in the Balkans, Alps, and Pyrenees mark the northern limit for tick survival. Under the warmer conditions predicted by future climate scenarios, tick expansion to new areas previously free of the vector is expected to increase, mainly in the Balkans and southern Russia, thus increasing the northern limit of the tick range.

Another area in which models can help understating the risks associated with tick-borne pathogen transmission is modeling 
vaccination strategies. It has been shown that immunization with tick antigens can reduce pathogen transmission by reducing tick populations and vector capacity (de la Fuente et al., 1998, 2006, 2007a,c; de la Fuente and Kocan, 2003, 2006; Labuda et al., 2006; Pedra et al., 2006; Narasimhan et al., 2007; Tsuji et al., 2007; Merino et al., 2011; Carreón et al., 2012). Gomes-Solecki et al. (2006) and Tsao et al. (2004) recently demonstrated the feasibility of vaccinating animal host populations to decrease the prevalence of tick-borne pathogens in ticks, thus reducing the risk for pathogen transmission to humans and animals. In this research, B. burgdorferi infections in I. scapularis were reduced when ticks fed on mice immunized with the bacterial protein OspA, possibly by blocking bacterial adhesion to the tick receptor. A dynamic model of B. burgdorferi transmission in mice was then developed by Tsao et al. (2012) to evaluate the effect of vaccinating mice for the control of Lyme disease. They showed that a mouse-targeted vaccine would reduce $B$. burgdorferi infection prevalence in ticks but to further reduce risks of human infection, vaccination should also target other host species and measures should be implemented to reduce tick populations by vaccination and/or acaricide application. However, these models need to incorporate other variables related to climate and factors described herein to fully explore the effect of vaccines on the control of pathogen transmission.

\section{CONCLUSION AND FUTURE DIRECTIONS}

Several reliable models use climate variables as drivers to predict the current and future distribution of ticks or even their particular phenological patterns. Populations of the tick vector are regulated by a series of admittedly complex factors and climate traits. However, the "risk," conceived as the probability for humans to get infected by tick-transmitted pathogens, is dependent upon a large array of genetic factors (at the pathogen, tick, and host levels), social factors, and the dynamics of competent reservoir hosts,

\section{REFERENCES}

Alberti, A., Addis, M. F., Sparango, O., Zobba, R., Chess, A. B., Cubeddu, T., Parpaglia, M. L. P., Ardu, M., and Pitta, M. (2005). Anaplasma phagocytophilum, Sardinia, Italy. Emerging Infect. Dis. 11, 1322-1323.

Alekseev, A. N., Chunikhin, S. P., Rukhkyan, M. Y., and Stefutkina, L. F. (1991). Possible role of Ixodidae salivary gland substrate as an adjuvant enhancing arbovirus transmission. Med. Parazitol. (Mosk) 1, 28-31.

Apanaskevich, D. A. (2004). Hostparasite relationships of the genus Hyalomma Koch, 1844 (Acari, Ixodidae) and their connection with microevolutionary process. Parazitologia 38, 515-523.

Apanaskevich, D. A., and Horak, I. V. (2008). The genus Hyalomma Koch, 1844: V- re-evaluation of the taxonomic rank of taxa comprising the $H$. (Euhyalomma) marginatum Koch complex of species (Acari: Ixodidae) with redescriptions of all parasitic stages and notes on biology. Int. J. Acarol. 34, 13-42.
Bacon, R. M., Kugler, K. J., and Mead, P. S. (2008). Surveillance for Lyme disease United States, 1992-2006. MMWR Surveill. Summ. 57, 1-9.

Baldridge, G. D., Scoles, G. A., Burkhardt, N. Y., Schloeder, B., Kurtti, T. J., and Munderloh, U. G. (2009). Transovarial transmission of Francisella-like endosymbionts and Anaplasma phagocytophilum variants in Dermacentor albipictus (Acari: Ixodidae). J. Med. Entomol. 46, 625-32.

Barandika, J. F., Hurtado, A., GarciaSanmartrin, J., Juste, R. A., Anda, P., and Garcia-Perez, A. L. (2008). Prevalence of tickborne zoonotic bacteria in questing adult ticks from northern Spain. Vector Borne

Belozerov, V. N. (1982). "Diapause and biological rhythms in ticks," in Physiology of Ticks, eds F. R. Obenchain and R. Galun (New York, NY: Pergamon Press), 469-500.

Busby, A. T., Ayllón, N., Kocan, K. M., Blouin, E. F., de la Fuente, G., Galindo, R. C., Villar, M., and de Zoonotic Dis. 8, 829-835.

thus adding further layers of complexity. Therefore, other than the modulation of the development and mortality rates of the tick vector, climate, and other factors may regulate the intrinsic rates of the population density of the many tick hosts available. It is necessary to understand how regional weather and pathogen infection rates affect the molecular events in the tick vector and pathogen transmission. The field of compared ecology and behavioral processes is still widely open, which needs new developments and harmonized approaches to extricate the complex processes at the host-vectorpathogen interface. Recent results support that climate is playing a pivotal role in the spread, seasonality, and abundance patterns of several tick species with economical importance and/or impact on human and animal health.

Future research directions include the development of models that could handle the complex relationships between cohorts of newly borne and adult reservoir hosts, integrating tick developmental and mortality rates into a dynamic framework. Currently, adequate methods do not exist to model the composition of tick populations, the impact of climate on the individuals in the population as related to tick questing activity. This is of special relevance to compute the infestation rates on hosts and estimate density-dependent mortality rates and thus the recruitment of individuals into the next tick activity season. This is expected to be of particular importance in the development of reliable R0 values.

\section{ACKNOWLEDGMENTS}

We thank members of our laboratories for fruitful discussions. This research was supported by EU FP7, ANTIGONE project number 278976, and the Spanish Secretaría de Estado de Investigación, Desarrollo e Innovación, Ministerio de Economía y Competitividad project BFU2011-23896. N. Ayllón was funded by MICINN, Spain.

la Fuente, J. (2012). Expression of heat-shock proteins and subolesin affects stress responses, Anaplasma phagocytophilum infection and questing behavior in the tick, Ixodes scapularis. Med. Vet. Entomol. 26, 92-102.

Cao, W. C., Zhan, L., He, J., Foley, J. E., de Vlas, S. J., Wu, X. M., Yang, H., Richardus, J. H., Habbema, J. D. (2006). Habbema. Natural Anaplasma phagocytophilum infection of ticks and rodents from a forest area of Jilin Province, China. Am. J. Trop. Med. Hyg. 75, 664-668.

Carreón, D., Pérez de la Lastra, J. M., Almazán, C., Canales, M., RuizFons, F., Boadella, M., MorenoCid, J. A., Villar, M., Gortázar, C., Reglero, M., Villarreal, R., and de la Fuente, J. (2012). Vaccination with BM86, subolesin and akirin protective antigens for the control of tick infestations in white tailed deer and red deer. Vaccine 30, 273-279.

Cumming, G. S. (2002). Comparing climate and vegetation as limiting factors for species ranges of African ticks. Ecology 83, 255-268.

Daniel, M., and Dusbabek, F. (1994). "Micrometeorological and microhabitat factors affecting maintenance and dissemination of tick-borne diseases in the environment," in Ecological Dynamics of Tick-Borne Zoonoses, eds D. E. Sonenshine and T. N. Mather (New York, NY: Oxford University Press), 91-138.

Danielova, V., Rudenko, N., Daniel, M., Holubova, J., Materna, J., Golovchenko, M., and Schwarzova, L. (2006). Extension of Ixodes ricinus ticks and agents of tick-borne diseases to mountain areas in the Czech Republic. Int. J. Med. Microbiol. 296(Suppl. 40), 48-53.

de la Fuente, J., Almazán, C., Blouin, E. F., Naranjo, V., and Kocan, K. M. (2006). Reduction of tick infections with Anaplasma marginale and A. phagocytophilum by targeting the tick protective antigen subolesin. Parasitol. Res. 100, 85-91. 
de la Fuente, J., Estrada-Peña, A., Venzal, J. M., Kocan, K. M., and Sonenshine, D. E. (2008). Overview: ticks as vectors of pathogens that cause disease in humans and animals. Front. Biosci. 13, 6938-6946.

de la Fuente, J., and Kocan, K. M. (2003). Advances in the identification and characterization of protective antigens for development of recombinant vaccines against tick infestations. Expert Rev. Vaccines 2, 583-593.

de la Fuente, J., and Kocan, K. M. (2006). Strategies for development of vaccines for control of ixodid tick species. Parasite Immunol. 28, 275-283.

de la Fuente, J., Kocan, K. M., and Blouin, E. F. (2007a). Tick vaccines and the transmission of tickborne pathogens. Vet. Res. Commun. 31(Suppl. 1), 85-90.

de la Fuente, J., Blouin, E. F., ManzanoRoman, R., Naranjo, V., Almazán, C., Pérez de la Lastra, J. M., Zivkovic, Z., Jongejan, F., and Kocan, K. M. (2007b). Functional genomic studies of tick cells in response to infection with the cattle pathogen, Anaplasma marginale. Genomics 90, 712-722.

de la Fuente, J., Almazán, C., Canales, M., Pérez de la Lastra, J. M., Kocan, K. M., and Willadsen, P. (2007c). A ten-year review of commercial vaccine performance for control of tick infestations on cattle. Anim. Health Res. Rev. 8, 23-28.

de la Fuente, J., Massung, R. F., Wong, S., Chu, F. K., Lutz, H., Meli, M., von Loewenich, F. D., Grzeszczuk, A., Torina, A., Caracappa, S., Mangold, A. J., Naranjo, V., Stuen, S., and Kocan, K. M. (2005). Sequence analysis of the msp4 gene of Anaplasma phagocytophilum strains. J. Clin. Microbiol. 43, 1309-1317.

de la Fuente, J., Rodríguez, M., Redondo, M., Montero, C., García-García, J. C., Méndez, L., Serrano, E., Valdés, M., Enriquez, A., Canales, M., Ramos, E., Boué, O., Machado, H., Lleonart, R., de Armas, C. A., Rey, S., Rodríguez, J. L., Artiles, M., and García, L. (1998). Field studies and costeffectiveness analysis of vaccination with GavacTM against the cattle tick Boophilus microplus. Vaccine 16, 366-373.

de la Fuente, J., Vicente, J., Höfle, U., Ruiz-Fons, F., Fernandez de Mera, I. G., Van den Bussche, R. A., Kocan, K. M., and Gortazar, C. (2004). Anaplasma infection in freeranging Iberian red deer in the region of Castilla-La Mancha, Spain. Vet. Microbiol. 100, 163-173.
Derdáková, M., Dudiòák, V., Brei, B., Brownstein, J. S., Schwartz, I., and Fish, D. (2004). Interaction and transmission of two Borrelia burgdorferi sensu stricto strains in a tick-rodent maintenance system. Appl. Environ. Microbiol. 70, 6783-6788.

Dsouli, N., Younsi-Kabachii, H., Postic, D., Nouira, S., Gern, L., and Bouattour, A. (2006). Reservoir role of lizard Psammodromus algirus in transmission cycle of Borrelia burgdorferi sensu lato (Spirochaetaceae) in Tunisia. J. Med. Entomol. 43, 737-742.

Dumler, J. S., Barbet, A. F., Bekker, C. P., Dasch, G. A., Palmer, G. H., Ray, S. C., Rikihisa, Y., and Rurangirwa, F. R. (2001). Reorganization of genera in the families Rickettsiaceae and Anaplasmataceae in the order Rickettsiales: unification of some species of Ehrlichia with Anaplasma, Cowdria with Ehrlichia and Ehrlichia with Neorickettsia, descriptions of six new species combinations and designation of Ehrlichia equi and "HGE agent" as subjective synonyms of Ehrlichia phagocytophila. Int. J. Syst. Evol. Microbiol. 51, 2145-2165.

Estrada-Peña, A. (1999). Geostatistics as predictive tools to estimate Ixodes ricinus (Acari: Ixodidae) habitat suitability in the western Palearctic from AVHRR satellite imagery. Exp. Appl. Acarol. 23, 337-349.

Estrada-Peña, A. (2002). Increasing habitat suitability in the United States for the tick that transmits Lyme disease: a remote sensing approach. Environ. Health Perspect. $110,635-640$.

Estrada-Peña, A. (2008). Climate, niche, ticks, and models: what they are and how we should interpret them. Parasitol. Res. 103(Supp. 1), 87-95.

Estrada-Peña, A., Jameson, L., Medlock, J., Vatansever, Z., and Tishkova, F. (2012a). The ecology of CrimeanCongo haemorrhagic fever virus: what we should know. Vector Borne Zoonotic Dis. (in press).

Estrada-Peña, A., Palomar, A. M., Santibáñez, P., Sánchez, N., Habela, M. A., Portillo, A., Romero, L., and Oteo, J. A. (2012b). Crimean-Congo hemorrhagic fever virus in ticks, southwestern Europe, 2010. Emerging Infect. Dis. 18, 179-180.

Estrada-Peña, A., Sánchez, N., and Estrada-Sánchez, A. (2012c). An assessment of the distribution and spread of Hyalomma marginatum in the western Palearctic under different climate scenarios. Vector Borne Zoonotic Dis. (in press).
Estrada-Peña, A., Martinez, J. M., Sanchez Acedo, C., Quilez, J., and Del Cacho, E. (2004). Phenology of the tick, Ixodes ricinus, in its southern distribution range (central Spain). Med. Vet. Entomol. 18, 387-397.

Estrada-Peña, A., Ortega, C., Sánchez, N., DeSimone, L., Sudre, B., Suk, J. E., and Semenza, J. C. (2011a). Correlation of Borrelia burgdorferi sensu lato prevalence in questing Ixodes ricinus ticks with specific abiotic traits in the western Palearctic. Appl. Environ. Microbiol. 77, 3838-3845.

Estrada-Peña, A., Avilés, M., and Martínez-Reoyo, M. J. (2011b). A population model to describe the distribution and seasonal dynamics of the tick Hyalomma marginatum in the Mediterranean basin. Transbound. Emerg. Dis. 58, 213-223.

Estrada-Peña, A., Vatansever, Z., Gargili, A., and Ergonul, O. (2010). The trend towards habitat fragmentation is the key factor driving the spread of Crimean-Congo haemorrhagic fever. Epidemiol. Infect. 138, 1194-1203.

Estrada-Peña, A., and Venzal, J. M. (2007). Climate niches of tick species in the Mediterranean region: modeling of occurrence data, distributional constraints, and impact of climate change. J. Med. Entomol. 44, 1130-1138.

Estrada-Peña, A., Venzal, J. M., Sánchez Acedo, C. (2006). The tick Ixodes ricinus: distribution and climate preferences in the western Palearctic. Med. Vet. Entomol. 20, 189-197.

Gaowa, W., Wu, D., Yoshikawa, Y., Ohashi, N., Kawamori, F., Sugiyama, K., Ohtake, M., Ohashi, M., Yamamoto, S., Kitano, T., Takada, N., and Kawabata, H. (2012). Detection and characterization of p44/msp2 transcript variants of Anaplasma phagocytophilum from naturally infected ticks and wild deer in Japan. Jpn. J. Infect. Dis. 65, 79-83.

Gatewood, A. G., Liebman, K. A., Vourc'H, G., Bunikis, J., Hamer, S. A., Cortinas, R., Melton, F., Cislo, P., Kitron, U., Tsao, J., Barbour, A. G., Fish, D., and Diuk-Wasser, M. A. (2009). Climate and tick seasonality predict Borrelia burgdorferi genotype distribution. Appl. Environ. Microbiol. 75, 2476-2483.

Gomes-Solecki, M. J. C., Brisson, D. R., and Dattwyler, R. J. (2006). Oral vaccine that breaks the transmission cycle of the Lyme disease spirochete can be delivered via bait. Vaccine 24, 4440-4449.

Gray, J. S. (2008). Ixodes ricinus seasonal activity: implications of global warming indicated by revisiting tick and weather data. Int. J. Med. Microbiol. 298(Suppl. 1), 19-24.

Gray, J. S., Dautel, H., Estrada-Peña, A., Kahl, O., and Lindgren, E. (2009). Effects of climate change on ticks and tick-borne diseases in Europe. Interdiscip. Perspect. Infect. Dis. 2009, 593232.

Guglielmone, A. A., Robbins, R. G., Apanaskevich, D. A., Petney, T. N., Estrada-Peña, A., Horak, I. G., Shao, R., and Barker, S. C. (2010). The Argasidae, Ixodidae and Nuttalliellidae (Acari: Ixodida) of the world: a list of valid species names. Zootaxa $2528,1-28$.

Hajdusek, O., Sojka, D., Kopacek, P., Buresova, V., Franta, Z., Sauman, I., Winzerling, J., and Grubhoffer, L. (2009). Knockdown of proteins involved in iron metabolism limits tick reproduction and development. Proc. Natl. Acad. Sci. U.S.A. 106, 1033-1038.

Hasle, G., Bjune, G. A., Midtheli, L., Roed, K. H., and Leinaas, H. P. (2011). Transport of Ixodes ricinus infected with Borrelia species to Norway by northward-migrating passerine birds. Ticks Tick Borne Dis. 2, 37-43.

Herrmann, C., and Gern, L. (2010). Survival of Ixodes ricinus (Acari: Ixodidae) under challenging conditions of temperature and humidity is influenced by Borrelia burgdorferi sensu lato infection. J. Med. Entomol. 47, 1196-1204.

Hodzic, E., Fish, D., Maretzki, C. M., de Silva, A. M., Feng, S., and Barthold, S. W. (1998). Acquisition and transmission of the agent of human granulocytic ehrlichiosis by Ixode scapularis ticks. J. Clin. Microbiol. 36, 3574-3578.

Holden, K., Boothby, J. T., Anand, S., and Massung, R. F. (2003). Detection of Borrelia burgdorferi, Ehrlichia chaffeensis, and Anaplasma phagocytophilum in ticks (Acari: Ixodidae) from a coastal region of California. J. Med. Entomol. 40, 534-539.

Hoogstraal, H. (1979). The epidemiology of tick-borne Crimean-Congo hemorrhagic fever in Asia, Europe, and Africa. J. Med. Entomol. 15, 307-417.

Hoogstraal, H., Kaiser, M. N., Traylor, M. A., Gaber, S., and Guindy, E. (1961). Ticks (Ixodidea) on birds migrating from Africa to Europe and Asia. Bull. World Health Organ. 24, 197-212.

Hoogstraal, H., Kaiser, M. N., Traylor, M. A., Guindy, E., and Gaber, S. (1963). Ticks (Ixodidea) on birds migrating from Europe and Asia to 
Africa. Bull. World Health Organ. 28, 235-262.

Jaenson, T. G. T., Jaenson, D. G. E., Eisen, L., Petersoon, E., and Lindgren, E. (2012). Changes in the geographical distribution and abundance of the tick Ixodes ricinus during the past 30 years in Sweden. Parasit. Vectors 5, 8.

Jin, H., Wei, F., Liu, Q., and Qian, J. (2012). Epidemiology and control of human granulocytic anaplasmosis: a systematic review. Vector Borne Zoonotic Dis. doi:10.1089/vbz. 2011.0753. [Epub ahead of print].

Jones, L. D., Hodgson, E., and Nuttall, P. A. (1989). Enhancement of virus transmission by tick salivary glands. J. Gen. Virol. 70, 1895-1898.

Jore, S., Viljugrein, H., Hofshagen, M., Brun-Hansen, H., Kristoffersen, A. B., Nygard, K., Brun, E., Ottesen, P., Saevik, B. K., and Ytrehus, B. (2011). Multi-source analysis reveals latitudinal and altitudinal shifts in range of Ixodes ricinus at its northern distribution limit. Parasit. Vectors 4, 84.

Jouda, A., Perret, J. L., and Gern, L. (2004). Ixodes ricinus density, and distribution and prevalence of Borrelia burgdorferi sensu lato infection along an altitudinal gradient. J. Med. Entomol. 41, 162-169.

Keirans, J. E., Needhma, G. R., and Oliver, J. H. (1999). "The Ixodes ricinus complex worldwide: diagnosis of the species in the complex, hosts and distribution," in Proceedings of the IXth International Congress of Acarology (Columbus, $\mathrm{OH}$ : Ohio Biological Survey).

Knudsen, E., Lindén, A., Ergon, T., Jonzén, J., Vik, J. O., Knape, J., Røer, J. E., and Stenseth, N. C. (2007). Characterizing bird migration phenology using data from standardized monitoring at bird observatories. Climate Res. 35, 59-77.

Kocan, K. M., de la Fuente, J., Blouin, E. F., and Garcia-Garcia, J. C. (2004). Anaplasma marginale (Rickettsiales: Anaplasmataceae): recent advances in defining host-pathogen adaptations of a tick-borne Rickettsia. Parasitology 129, 285-300.

Kongsuwan, K., Josh, P., Zhu, Y., Pearson, R., Gough, J., and Colgrave, M. L. (2010). Exploring the midgut proteome of partially fed female cattle tick (Rhipicephalus (Boophilus) microplus). J. Insect Physiol. 56, 212-226.

Kurtenbach, K., Hanincová, K., Tsao, J. I., Margos, G., Fish, D., and Ogden, N. H. (2006). Fundamental processes in the evolutionary ecology of Lyme borreliosis. Nat. Rev. Microbiol. 4, 660-669.
Labuda, M., Jones, L. D., Williams, T., and Nuttall, P. A. (1993a). Enhancement of tick-borne encephalitis virus transmission by tick salivary gland extracts. Med. Vet. Entomol. 7, 193-196.

Labuda, M., Jones, L. D., Williams, T., Danielova, V., and Nuttall, P. A. (1993b). Efficient transmission of tick-borne encephalitis virus between cofeeding ticks. J. Med. Entomol. 30, 295-299.

Labuda, M., Trimnell, A. R., Lickova, M., Kazimirova, M., Davies, G. M., Lissina, O., Hails, R. S., and Nuttall, P. A. (2006). An antivector vaccine protects against a lethal vectorborne pathogen. PLoS Pathog. 2, e27. doi:10.1371/journal.ppat.0020027

Lefcort, H., and Durden, L. A. (1996). The effect of infection with Lyme disease spirochetes (Borrelia burgdorferi) on the phototaxis, activity, and questing height of the tick vector Ixodes scapularis. Parasitology 113, 97-103.

Lew-Tabor, A. E., Moolhuijzen, P. M., Vance, M. E., Kurscheid, S., Valle, M. R., Jarrett, S., Minchin, C. M., Jackson, L. A., Jonsson, N. N., Bellgard, M. I., and Guerrero, F. D. (2010). Suppressive subtractive hybridization analysis of Rhipicephalus (Boophilus) microplus larval and adult transcript expression during attachment and feeding. Vet. Parasitol. 167, 304-320.

Lindgren, E., and Gustafson, R. (2001). Tick-borne encephalitis in Sweden and climate change. Lancet 358, 16-18.

Lindgren, E., Tälleklint, L., and Polfeldt, T. (2000). Impact of climatic change on the northern latitude limit and population density of the diseasetransmitting European tick Ixodes ricinus. Environ. Health Perspect. 108, 119-123.

Macaluso, K. R., Mulenga, A., Simser, J. A., and Azad, A. F. (2003). Differential expression of genes in uninfected and rickettsia-infected Dermacentor variabilis ticks as assessed by differential-display PCR. Infect. Immun. 71, 6165-6170.

MacLeod, J. (1932). Preliminary studies in tick transmission of louping ill. II. A study of the reaction of sheep to tick infestation. Vet. J. 88, 276-284.

Maltezou, H. C., Andonova, L., Andraghetti, R., Bouloy, M., Ergonul, O., Jongejan, F., Kalvatchev, N., Nichol, S., Niedrig, M., Platonov, A., Thomson, G., Leitmeyer, K., and Zeller, H. (2010). Crimean-Congo hemorrhagic fever in Europe: current situation calls for preparedness. Euro Surveill. 15, 19504.
Mantke, O. D., Schädler, R., and Niedrig, M. (2008). A survey on cases of tick-borne encephalitis in European countries. Euro Surveill. 13, 18848.

Massung, R. F., Mather, T. N., and Levin, M. L. (2006). Reservoir competency of goats for the Ap-variant 1 strain of Anaplasma phagocytophilum. Infect. Immun. 74, 1373-1375.

Matser, A., Hartemink, N., Heesterbeek, H., Galvani, A., and Davis, S. (2009). Elasticity analysis in epidemiology: an application to tick-borne infections. Ecol. Lett. 12, 1298-1305.

McQuiston, J., Levy, C., Traeger, M., Piontkowski, S., Stewart, T., Nicholson, W., and Regan, J. (2010). "Rocky mountain spotted fever associated with Rhipicephalus sanguineus ticks: from emergence to establishment of an enzootic focus in the United States," in 2010 International Conference on Emerging Infectious Diseases, Atlanta, GA.

Merino, O., Almazán, C., Canales, M., Villar, M., Moreno-Cid, J. A., Galindo, R. C., and de la Fuente, J. (2011). Targeting the tick protective antigen subolesin reduces vector infestations and pathogen infection by Anaplasma marginale and Babesia bigemina. Vaccine 29, 8575-8579.

Mulenga, A., Blandon, M., and Khumthong, R. (2007). The molecular basis of the Amblyomma americanum tick attachment phase. Exp. Appl. Acarol. 41, 267-287.

Mulenga, A., Macaluso, K. R., Simser, J. A., and Azad, A. F. (2003). Dynamics of Rickettsia-tick interactions: identification and characterization of differentially expressed mRNAs in uninfected and infected Dermacentor variabilis. Insect Mol. Biol. 12, 185-193.

Naranjo, V., Ruiz-Fons, F., Höfle, U., Fernández de Mera, I. G., Villanua, D., Almazan, C., Torina, A., Caracappa, S., Kocan, K. M., Gortazar, C., and de la Fuente, J. (2006). Molecular epidemiology of human and bovine anaplasmosis in southern Europe. Ann. N. Y. Acad. Sci. 1078, 95-99.

Narasimhan, S., Deponte, K., Marcantonio, N., Liang, X., Royce, T. E., Nelson, K. F., Booth, C. J., Koski, B., Anderson, J. F., Kantor, F., and Fikrig, E. (2007). Immunity against Ixodes scapularis salivary proteins expressed within 24 hours of attachment thwarts tick feeding and impairs Borrelia transmission. PLoS ONE 2, e451. doi:10.1371/journal.pone. 0000451

Narasimhan, S., Santiago, F., Koski, R. A., Brei, B., Anderson, J. F., Fish, D., and Fikrig, E. (2002). Examination of the Borrelia burgdorferi transcriptome in Ixodes scapularis during feeding. J. Bacteriol. 184, 3122-3125.

Nuttall, P. A., and Labuda, M. (2008). "Saliva-assisted transmission of tickborne pathogens," in Ticks: Biology, Disease and Control, eds A. S. Bowman and P. A Nuttall (Cambridge: Cambridge University Press), 205-219.

Ogden, N. H., Bigras-Poulin, M., O'Callaghan, C. J., Barker, I. K., Lindsay, L. R., Maarouf, A., SmoyerTomic, K. E., Waltner-Toews, D., and Charron, D. (2005a). A dynamic population model to investigate effects of climate on geographic range and seasonality of the tick Ixodes scapularis. Int. J. Parasitol. 35, 375-389.

Ogden, N. H., Bigras-Poulin, M., O'Callaghan, C. J., Barker, I. K., Kurtenbcah, K., Lindsay, L. R., and Charron, D. F. (2005b). Vector seasonality, host infection dynamics and fitness of pathogens transmitted by the tick Ixodes scapularis. Parasitology 134, 209-227.

Ogden, N. H., Lindsay, L. R., Beauchamp, G., Charron, D., Maarouf, A., O'Callaghan, C. J., Waltner-Toews, D., and Barker, I. K. (2004). Investigation of the relationships between temperature and development rates of the tick Ixodes scapularis (Acari: Ixodidae) in the laboratory and field. J. Med. Entomol. 41, 622-633.

Paddock, C. D., Finley, R. W., Wright, C. S., Robinson, H. N., Schrodt, B. J., Lane, C. C., Ekenna, O., Blass, M. A., Tamminga, C. L., Ohl, C. A., McLellan, S. L., Goddard, J., Holman, R. C., Openshaw, J. J., Sumner, J. W. Zaki, S. R., and Eremeeva, M. E. (2008). Rickettsia parkeri rickettsiosis and its clinical distinction from Rocky Mountain spotted fever. Clin. Infect. Dis. 47, 1188-1196.

Parola, P., Paddock, C. D., and Raoult, D. (2005). Tick-borne rickettsioses around the world: emerging diseases challenging old concepts. Clin. Microbiol. Rev. 18, 719-756.

Parola, P., and Raoult, D. (2001). Tickborne bacterial diseases emerging in Europe. Clin. Microbiol. Infect. 7, 80-83.

Pattnaik, P. (2006). Kyasanur forest disease: an epidemiological view in India. Rev. Med. Virol. 16, 151-165.

Pedra, J. H., Narasimhan, S., Deponte, K., Marcantonio, N., Kantor, F. S., and Fikrig, E. (2006). Disruption of the salivary protein 14 in Ixodes scapularis nymphs and impact on pathogen acquisition. Am. J. Trop. Med. Hyg. 75, 677-682. 
Perret, J.-L., Guerin, P., Diehl, P. A., Vlimant, M., and Gern, L. (2003). Darkness favours mobility and saturation deficit limits questing duration in Ixodes ricinus, the tick vector of Lyme disease in Europe. J. Exp. Biol. 206, 1809-1815.

Perret, J.-L., Guigoz, E., Rais, O., and Gern, L. (2000). Influence of saturation deficit and temperature on Ixodes ricinus tick questing activity in a Lyme borreliosis-endemic area (Switzerland). Parasitol. Res. 86, 554-557.

Phillips, S. J., Anderson, R. P., and Schapire, R. E. (2006). Maximum entropy modeling of species geographic distributions. Ecol. Modell. 190, 231-259.

Rachinsky, A., Guerrero, F. D., and Scoles, G. A. (2007). Differential protein expression in ovaries of uninfected and Babesia-infected southern cattle ticks, Rhipicephalus (Boophilus) microplus. Insect Biochem. Mol. Biol. 37, 1291-1308.

Rachinsky, A., Guerrero, F. D., and Scoles, G. A. (2008). Proteomic profiling of Rhipicephalus (Boophilus) microplus midgut responses to infection with Babesia bovis. Vet. Parasitol.152, 294-313.

Randolph, S. E. (1997). Abiotic and biotic determinants of the seasonal dynamics of the tick Rhipicephalus appendiculatus in South Africa. Med. Vet. Entomol. 11, 25-37.

Randolph, S. E. (2001). The shifting landscape of tick- borne zoonoses: tick-borne encephalitis and Lyme borreliosis in Europe. Philos. Trans. R. Soc. Lond. B Biol. Sci. 356, 1045-1056.

Randolph, S. E. (2004). Tick ecology: processes and patterns behind the epidemiological risk posed by ixodid ticks as vectors. Parasitology 129, 37-65.

Randolph, S. E. (2008). Tick-borne encephalitis in Central and Eastern Europe: consequences of political transition. Microbes Infect. 10, 209-216.

Randolph, S. E. (2009). Tick-borne diseases systems emerge from the shadows: the beauty lies in molecular details, the message in epidemiology. Parasitology 136, 1403-1413.

Randolph, S. E., Green, R. M., Hoodless, A. N., and Peacey, M. F. (2002). An empirical quantitative framework for the seasonal population dynamics of the tick Ixodes ricinus. Int. J. Parasitol. 32, 979-989.

Randolph, S. E., Green, R. M., Peacey, M. F., and Rogers, D. J. (2000). Seasonal synchrony: the key to tick-borne encephalitis foci identified by satellite data. Parasitology 121, 15-23.

Randolph, S. E., and Rogers, D. J. (2000). Fragile transmission cycles of tickborne encephalitis virus may be disrupted by predicted climate change. Proc. R. Soc. Lond. B Biol. Sci. 267, 1741-1744.

Randolph, S. E., and Sumilo, D. (2007). "Tick-borne encephalitis in Europe: dynamics of changing risk," in Emerging Pests and Vector-borne Disease in Europe, eds W. Takken and B. G. J. Knols (Wageningen: Wageningen Academic Publishers), 187-206.

Reichard, M. V., Manzano Roman, R., Kocan, K. M., Blouin, E. F., de la Fuente, J., Snider, T. A., Heinz, R. E., Massung, R. F., West, M. D., and Little, S. E. (2009). Inoculation of white-tailed deer (Odocoileus virginianus) with Ap-V1 or NY18 strains of Anaplasma phagocytophilum and microscopic demonstration of Ap-V1 in Ixodes scapularis adults that acquired infection from deer as nymphs. Vector Borne Zoonotic Dis. 9, 565-568.

Ribeiro, J. M., Alarcon-Chaidez, F., Francischetti, I. M., Mans, B. J., and Mather, T. N. (2006). An annotated catalog of salivary gland transcripts from Ixodes scapularis ticks. Insect Biochem. Mol. Biol. 36, 111-129.

Rikihisa, Y. (2010). Anaplasma phagocytophilum and Ehrlichia chaffeensis: subversive manipulators of host cells. Nat. Rev. Microbiol. 8, 328-339.

Rudenko, N., Golovchenko, M., Edwards, M. J., and Grubhoffer, L. (2005). Differential expression of Ixodes ricinus tick genes induced by blood feeding or Borrelia burgdorferi infection. J. Med. Entomol. 42, 36-41.

Schauber, E. M., and Ostfeld, R. S. (2002). Modeling the effects of reservoir competence decay and demographic turnover in Lyme disease ecology. Ecol. Appl. 12, 1142-1162.

Schulze, T. L., Jordan, R. A., and Hung, R. W. (2001). Effects of selected meteorological factors on diurnal questing of Ixodes scapularis and Amblyomma americanum (Acari: Ixodidae). J. Med. Entomol. 38, 318-324.

Sréter, T., Sréter-Lancz, Z., Széll, Z., and Kálmán, D. (2004). Anaplasma phagocytophilum: an emerging tick-borne pathogen in Hungary and Central Eastern Europe. Ann. Trop. Med. Parasitol. 98, 401-405.

Stuen, S. (2007). Anaplasma phagocytophilum - the most widespread tick-borne infection in animals in Europe. Vet. Res. Commun. 31(Suppl. 1), 79-84.

Sukumaran, B., Narasimham, S., Anderson, J. F., DePonte, K., Marcantonio, K., Krishnan, M. N., Fish, D. Telford, S. R., Kantor, F. S., and Fikrig, E. (2006). An Ixodes scapularis protein required for survival of Anaplasma phagocytophilum in tick salivary glands. J. Exp. Med. 6, 1507-1517.

Sumilo, D., Asokliene, L., Bormane, A., Vasilenko, V., Golovljova, I., and Randolph, S. E. (2007). Climate change cannot explain the upsurge of tick-borne encephalitis in the Baltics. PLoS ONE 2, e500. doi:10.1371/journal.pone.0000500

Sumilo, D., Bormane, A., Asokliene, L., Lucenko, I., Vasilenko, V., and Randolph, S. E. (2006). Tick-borne encephalitis in the Baltic States: identifying risk factors in space and time. Int. J. Med. Microbiol. 296, 76-79.

Sumilo, D., Bormane, A., Asokliene, L., Vasilenko, V., Golovljova, I., AvsicZupanc, T., Hubalek, Z., and Randolph, S. E. (2008). Socio-economic factors in the differential upsurge of tick-borne encephalitis in central and eastern Europe. Rev. Med. Virol. 18, 81-95.

Swanepoel, R., Struthers, J. K., Shepherd, A. J., McGillivray, G. M., Nel, M. J., and Jupp, P. G. (1983). Crimean-Congo hemorrhagic fever in South Africa. Am. J. Trop. Med. Hyg. 32, 1407-1415.

Tsao, J. I., Wootton, J. T., Bunikis, J. Luna, M. G., Fish, D., and Barbour, A. G. (2004). An ecological approach to preventing human infection: vaccinating wild mouse reservoirs intervenes in the Lyme disease cycle. Proc. Natl. Acad. Sci. U.S.A. 101, 18159-18164.

Tsao, K., Fish, D., and Galvani, A. P. (2012). Predicted outcomes of vaccinating wildlife to reduce human risk of Lyme disease. Vector Borne Zoonotic Dis. doi:10.1089/vbz.2011.0731. [Epub ahead of print].

Tsuji, N., Battsetseg, B., Boldbaatar, D., Miyoshi, T., Xuan, X., Oliver, J. H. Jr., and Fujisaki, K. (2007). Babesial vector tick defensin against Babesia sp. parasites. Infect. Immun. 75, 3633-3640.

Tutar, L., and Tutar, Y. (2010). Heat shock proteins; an overview. Curr. Pharm. Biotechnol. 11, 216-222.

Vail, S. C., and Smith, G. J. (1998). Air temperature and relative humidity effects on behavioral activity of blacklegged tick (Acari: Ixodidae) nymphs in New Jersey. J. Med. Entomol. 35, 1025-1028.

Vail, S. C., and Smith, G. J. (2002). Vertical movement and posture of blacklegged tick (Acari: Ixodidae) nymphs as a function of temperature and relative humidity in laboratory experiments. J. Med. Entomol. 39, 842-846.

Villar, M., Ayllón, N., Busby, A. T., Galindo, R. C., Blouin, E. F., Kocan, K. M., Bonzón-Kulichenko, E., Zivkovic, Z., Almazán, C., Torina, A., Vázquez, J., and de la Fuente, J. (2010). Expression of heat shock and other stress response proteins in ticks and cultured tick cells in response to Anaplasma spp. infection and heat shock. Int. J. Proteomics 657261.

Woldehiwet, Z. (2010). The natural history of Anaplasma phagocytophilum. Vet. Parasitol. 167, 108-122.

Zeman, P., and Benes, C. (2004). A tickborne encephalitis ceiling in Central Europe has moved upwards during the last 30 years: possible impact of global warming? Int J. Med. Microbiol. 293(Suppl. 37), 48-54.

Zivkovic, Z., Blouin, E. F., ManzanoRoman, R., Almazán, C., Naranjo, V., Massung, R. F., Jongejan, F., Kocan, K. M., and de la Fuente, J. (2009). Anaplasma phagocytophilum and A. marginale elicit different gene expression responses in ticks and cultured tick cells. Comp. Funct. Genomics 2009, 705034.

Conflict of Interest Statement: The authors declare that the research was conducted in the absence of any commercial or financial relationships that could be construed as a potential conflict of interest.

Received: 31 January 2012; accepted: 05 March 2012; published online: 27 March 2012.

Citation: Estrada-Peña A, Ayllón N and de la Fuente J (2012) Impact of climate trends on tick-borne pathogen transmission. Front. Physio. 3:64. doi: 10.3389/fphys.2012.00064

This article was submitted to Frontiers in Systems Biology, a specialty of Frontiers in Physiology.

Copyright (C) 2012 Estrada-Peña, Ayllón and de la Fuente. This is an open-access article distributed under the terms of the Creative Commons Attribution Non Commercial License, which permits noncommercial use, distribution, and reproduction in other forums, provided the original authors and source are credited. 